\title{
Validity, Reliability, and Invariance of the Greek Version the Physical Activity Perceived Barriers Scale
}

\author{
Ioanna Konstantinos Tsamita ${ }^{1}$, Athanasios Sakis Pappous ${ }^{2}$ and Konstantinos Karteroliotis ${ }^{1}$ \\ 1. Department of Sports Medicine and Biology of Exercise, Faculty of Physical Education and Sport Science, National and \\ Kapodistrian University of Athens, Athens 17237, Greece \\ 2. School of Sport \& Exercise Sciences, University of Kent at Medway, Chatham ME4 4AG, United Kingdom
}

\begin{abstract}
The study aimed to examine the validity, reliability, and factorial invariance across gender of the PAPBS (Physical Activity Perceived Barriers Scale) in Greek children. 613 students (322 boys and 291 girls) from a city of Greece completed the above scale in 3 periods during a school year. Confirmatory factor analysis was applied. Strong evidence was found for the hypothesized second-order factor structure of the physical activity perceived barriers scale in the 3 measurements (comparative fit index $=0.951,0.933,0.922$, and root mean square error of approximation $=0.061,0.069,0.074$ ). The scale's internal consistency was supported satisfactorily, whereas correlations coefficients between scale and several physical activity scores were significant moderate to high. Finally, results provided support of the invariance of the first- and second-order factor loadings and invariance structural residuals, but weak support of the invariance of the residual variance of observed variables of the examined scale across gender. The findings suggest that physical activity perceived barriers scale is appropriate for use with Greek children and it is considered as a useful tool for researches interested in studying the children's participation in physical activity.
\end{abstract}

Key words: Psychometrics, construct validity, health, fitness.

\section{Introduction}

Children's participation in PA (physical activity) is known to have many physical, psychological, and emotional health benefits during childhood and later in life [1]. Despite the health benefits of regular PA, children do not participate in PA and failing to meet established guideline of 60 minutes or more of moderate-to-vigorous PA daily [2]. This finding reinforces the need for intervention programs to increase children's PA. To guide the development and implementation of such programs, it is important to understand the various biological, social, environmental, and psychological factors that influence activity behavior in children [3, 4]. Among psychological factors, that are the most-researched ones, perceived barriers to PA are an essential

Corresponding author: Ioanna Tsamita, Ph.D., physical education school consultant, research fields: children's physical activity and dietary habits, physical education. E-mail: tsamitaioanna@gmail.com. component which is significantly correlated with PA maintenance in children $[5,6]$.

Perceived barriers, which are the individual's opinion of the tangible costs of an action or behavior, are an important factor related to health behavior and the most significant one in determining behavior change [7]. More specifically, the presence of perceived barriers decreases the likelihood of engaging in preventive health practices, especially if they outweigh the perceived benefits of doing so [8]. Consequently, in trying to increase PA, it is obvious that the perceived barriers should be overcome for a new behavior to be adopted.

In relevant studies of children, the most frequently cited barriers to PA were time constraints, schoolwork, lack of interest/desire, tiredness, lack of motivation, emotional symptoms, and unsuitable weather [9-11]. Also, it is reported that perceived barriers correlated negatively with children's PA and sports, and were a major inverse predictor of PA, indicating that students 
who perceive fewer barriers to PA are more likely to participate in PA, than students who perceive more barriers [5, 12]. Therefore, perceived barriers to children's PA should be well understood and be measured validly and reliably in order to contribute successfully to intervention programs seeking to increase children's PA.

Most researchers, however, that have examined the relationship between perceived barriers and PA used scales that have not been adequately validated. Brown et al. [13], in their systematic review, found only six studies that have examined the validity and reliability of perceived barriers to PA construct in children. They reported test-retest reliability coefficients ranging from 0.52 to 0.82 and Cronbach's alpha ranging from 0.55 to 0.85 . Furthermore, nearly all research examining perceived barriers utilized measures adapted from other studies or previous populations such as adults. Finally, few studies have established the factorial validity and invariance of the perceived barriers to children's PA scale to ensure that this construct is being measured similarly in different groups of people or at separate time [14, 15].

$\mathrm{Wu}$ et al. [16] examined the validity and reliability of a perceived barriers to PA scale with Taiwanese adolescents. The scale had 12 items and included three separate factors (time constraints, environmental surroundings, and personal issues). Cronbach's alpha for these subscales were $0.69,0.72$, and 0.71 , respectively. Furthermore, the construct validity of the scale was supported by examining the correlation between adolescent's perceived barriers and duration of PA.

To date, no factorial data, or psychometric properties of the perceived barriers to PA are available in the Greek language, hence prompting the present study. The aim of the present research, therefore, was to: (1) assess the factorial validity; (2) evaluate the factorial invariance across gender; (3) test the internal consistency and (4) further explore the construct validity with regard to the relationship to scores of PA, of a scale that assesses the perceived barriers to PA among Greek children.

\section{Material and Methods}

\subsection{Participants}

Participants were 613 fifth and sixth-grade students (322 boys and 291 girls) of the 5th and 6th grade from 12 primary schools in a Greek city.

\subsection{Measures}

The perceived barriers to PA were measured by subjects' responses to 12 items of PAPBS (Physical Activity Perceived Barriers Scale) that was used by $\mathrm{Wu}$ et al. [16] in relevant study with Taiwanese adolescents, regarding beliefs about barriers that they perceive as preventing them from performing PA (e.g., "I don't exercise because I don't have time", or "I don't exercise because I don't have a good place to exercise" (Table A1)). Participants responded to a 5 -point continuum $(1=$ "strongly disagree" to $5=$ "strongly agree"). Wu et al. [16] proposed a second-order factor model with an overall barrier factor having paths to the three subfactors or first-order factors. The first-order factor of PAPBS was "personal issues" that included 5 items, the second first-order factor was "environmental surroundings" having 4 items and finally the third first-order factor "time constraints" included 3 items. They also demonstrated acceptable validity and internal consistency of the scale in two groups of Taiwanese adolescents [16].

The PA was assessed by the SAPAC (Self Administered Physical Activity Checklist) [17] that consists of a list of 21 physical activities which the children used to participate (Table A2). Students reported the minutes they spent in each activity during three time periods of the previous day, before school, during school, and after school. They were instructed to report engaging in an activity only if they did so for 5 min or more "at one time". For every activity, students reported whether it caused them to "breathe 
hard or feel tired none, some, or most of the time". This rating provided a subjective index of intensity. The questionnaire was administered to an entire class simultaneously, in three consecutive days. All physical activities in the SAPAC were calculated in terms of: (1) physical activity METs score (MVPA METs) (min of activity X MET value); (2) weighted activity MET score (weighted MVPA METs) (min of activity $X$ MET value $X$ intensity rating) and (3) minutes of moderate to vigorous physical activity (min of MVPA). A recent study in Greece has demonstrated acceptable validity, reliability, and internal consistency of the SAPAC in young children [18].

\subsection{Procedures}

Students were assessed at the beginning (October), in the middle (February), and at the end (May) of the school year 2009-2010 from one group of trained physical education teachers. They completed PAPBS and SAPAC in groups per class during a two hours period. Students agreed to participate in the study after their parents gave a written informed consent. The anonymity and the protection of the students were ensured. The study had the permission of the Greek Ministry of Education and the school authorities.

\subsection{Statistical Analysis}

Statistical analyses of data involved: (1) CFA (confirmatory factor analysis); (2) factorial invariance across gender; (3) Cronbach's alpha, inter-item correlation, corrected item-total correlation to test the internal consistency of the examined scale and (4) Pearson's product moment correlation coefficient to further explore the construct validity of the scale. The factorial structure of PAPBS was examined by using CFA with the ML (maximum likelihood) technique. Data were analyzed using the Amos 18.0 statistical software [19].

The hypothesized second-order factor model was specified in the following way: (1) responses to the
PAPBS could be explained by three first-order factors ("personal issues", "environmental surroundings", "time constraints"), and one second-order factor ("perceived barriers"); (2) each item would have a non-zero loading on the first-order factor that it was designed to measure, and zero loadings on the other two first-order factors; (3) errors terms associated with each item would be uncorrelated and (4) covariation among the three first-order factors would be explained fully by their regression on the second-order factor [20].

In the present study, model fit was assessed using various absolutes as well as comparative/incremental fit indexes. The chi-square statistic, an absolute fit index, is a classic test that assesses exact fit of the specified model to the data. However, the chi-square is very sensitive to sample size or violations of the multivariate normality assumptions and therefore the fit of the model is often evaluated by means of a group of descriptive and comparative/incremental fit indices [21]. Contrary to the chi-square test, which examines whether the hypothesized model is correct or not, the RMSEA (root mean square error of approximation) [22] is another absolute fit index which estimates how well the fitted model approximates the population covariance matrix per degree of freedom. Browne and Cudeck [23] suggested that RMSEA value smaller than 0.05 are indicative of close fit, and values smaller than 0.08 are still considered reasonable. RMSEA 90\% CI is also used to assess hypotheses of close fit (RMSEA < 0.05) and not-close fit (RMSEA > 0.05). Finally, the GFI (goodness of-fit) index is applied with values ranging from 0 (poor fit) to 1.0 (perfect fit).

Comparative/incremental fit indexes compare the fit of the model of interest and alternative nested models. The CFI (comparative fit index) compares the adequacy of the hypothesized model in relation to an independent (null) model which assumes that all variables are uncorrelated. The Bentler and Bonett's [24] NFI (normed fit index) is an alternative to CFI 
that estimates the relative improvement per degree of freedom of the hypothesized model over a baseline model. CFI and NFI values approximating 1.0 indicate perfect fit, whereas values below 0.90 indicate a need to respecify the model.

Factorial invariance of PAPBS, with respect to gender, was examined using multiple group analysis. To compare the alternative models, the $\chi^{2}$ difference test $\left(\Delta \chi^{2}\right)$ and $\Delta C F I$ were used. Marsh [25] discussed that the tests of statistical significance of change in $\Delta \chi^{2}$ are suffering from same problems as the tests of statistical significance in regular confirmatory analysis. Marsh argued the use of other descriptive model fit indexes such as GFI, CFI, and RMSEA in testing the hypothesis of group invariance. Furthermore, Cheung and Rensvold [26] suggested that change in CFI values across the testing in each step of the sequential multi-group invariance analysis is warranted. More specifically, they have proposed a criterion of -0.01 in CFI between more and less restrictive invariance models for the rejection of the null hypothesis in testing the multi-group factorial invariance. A number of researchers have used this criterion in evaluating the multi-group factorial invariance in CFA models $[27,28]$.

To test the internal consistency of the scale, the following indexes are estimated: (1) inter-item correlations; (2) item-total correlations and (3) Cronbach's alpha coefficient. For an acceptable internal consistency, the Cronbach's alpha should exceed 0.70 [29].

Finally, construct validity, that is the extent to which a test measures the intended construct, was examined by estimating the bivariate correlations between the PAPBS and PA (total METs, weights METs, min of MVPA) values.

\section{Results}

The summary statistics for the CFA are presented in Table 1. As shown, all the standardized item loadings were statistically significant at the 0.05 level, ranging from 0.52 to 0.85 in all three measurements, being absolutely satisfactory $(>0.40)$. Also, the squared multiple correlations $\left(\mathrm{R}^{2}\right)$, that provide a direct index of performance of each factor, revealed strong evidence for the factorial validity of the hypothesized model. The $\mathrm{R}^{2}$ values ranged from 0 to 1 , with large $\mathrm{R}^{2}$, represent the proportion of variance explained in each item by its corresponding factor. As shown in Table 1 , all $\mathrm{R}^{2}$ values were satisfactory indicating that all items were loaded on their designated factors, in all three measurements.

The analysis of the goodness-of-fit indexes of the propose second-order model showed that: (1) all GFI, NFI, and CFI indexes were acceptable $(>0.900)$ and (2) the RMSEA indexes ranged from 0.061 to 0.074 , indicating acceptable fit of the proposed model to the data in all three assessments. More specifically, the chi-square statistic values were $\chi_{(\mathrm{df})}^{2}=166.017_{(51)}, P=$ $0.000, \chi_{(\mathrm{df})}^{2}=201.180_{(51)}, P=0.000$ and $\chi_{(\mathrm{df})}^{2}=$ $219.640_{(51)}, P=0.000$, in the three measurements, respectively. Also, the fit indexes were GFI $=0.956$, $\mathrm{NFI}=0.931, \mathrm{CFI}=0.951$ in the first measurement, $\mathrm{GFI}=0.947, \mathrm{NFI}=0.913, \mathrm{CFI}=0.933$ in the second measurement and GFI $=0.943, \mathrm{NFI}=0.901, \mathrm{CFI}=$ 0.922 in the third measurement. Finally, the RMSEA (90\% CI) indexes were 0.061 (0.051-0.071), 0.069 (0.059-0.080) and $0.074(0.064-0.084)$ in the three measurements, respectively.

Furthermore, the 12-item hierarchical model of the PAPBS was tested for invariance across gender in all three measurements. The model was initially tested for each group (boys, girls) separately. This allowed the adequacy of the model to be assessed within each group prior to the multi-group invariance analysis. According to the results, the hypothesized model in group of boys was a good representation of the data, since the model's fit indexes were acceptable. However, results indicated that the proposed model for girls wasn't fully supported by all fit indexes (see Table 2).

Table 2 also contains the fit indexes for each step of 
Table 1 Results of confirmatory factor analyses $(N=613)$.

\begin{tabular}{|c|c|c|c|c|c|c|c|c|c|}
\hline \multicolumn{10}{|c|}{ Physical Activity Perceived Barriers Scale } \\
\hline \multirow[b]{2}{*}{ Items } & \multicolumn{3}{|c|}{ 1st measurement } & \multicolumn{3}{|c|}{ 2nd measurement } & \multicolumn{3}{|c|}{ 3rd measurement } \\
\hline & SRW & $\mathrm{V}$ & $\mathrm{R}^{2}$ & SRW & $\mathrm{V}$ & $\mathrm{R}^{2}$ & SRW & $\mathrm{V}$ & $\mathrm{R}^{2}$ \\
\hline & \multicolumn{9}{|c|}{ Personal issues } \\
\hline 8 & 0.54 & 0.70 & 0.30 & 0.57 & 0.65 & 0.33 & 0.59 & 0.57 & 0.35 \\
\hline 9 & 0.59 & 0.42 & 0.35 & 0.56 & 0.39 & 0.32 & 0.58 & 0.37 & 0.34 \\
\hline 10 & 0.62 & 0.54 & 0.38 & 0.65 & 0.52 & 0.42 & 0.64 & 0.46 & 0.41 \\
\hline 11 & 0.55 & 0.57 & 0.30 & 0.56 & 0.51 & 0.31 & 0.52 & 0.51 & 0.27 \\
\hline \multirow[t]{2}{*}{12} & 0.61 & 0.53 & 0.37 & 0.60 & 0.48 & 0.36 & 0.61 & 0.45 & 0.37 \\
\hline & \multicolumn{9}{|c|}{ Environmental surroundings } \\
\hline 3 & 0.69 & 0.50 & 0.47 & 0.67 & 0.50 & 0.45 & 0.66 & 0.45 & 0.44 \\
\hline 4 & 0.68 & 0.39 & 0.46 & 0.66 & 0.36 & 0.44 & 0.62 & 0.33 & 0.39 \\
\hline 5 & 0.61 & 0.50 & 0.37 & 0.59 & 0.45 & 0.35 & 0.58 & 0.44 & 0.34 \\
\hline \multirow[t]{2}{*}{6} & 0.66 & 0.55 & 0.44 & 0.65 & 0.52 & 0.43 & 0.63 & 0.51 & 0.40 \\
\hline & \multicolumn{9}{|c|}{ Time constraints } \\
\hline 1 & 0.85 & 0.27 & 0.72 & 0.84 & 0.29 & 0.71 & 0.79 & 0.35 & 0.62 \\
\hline 2 & 0.78 & 0.33 & 0.62 & 0.71 & 0.42 & 0.50 & 0.73 & 0.35 & 0.53 \\
\hline 7 & 0.74 & 0.41 & 0.55 & 0.75 & 0.39 & 0.57 & 0.74 & 0.33 & 0.54 \\
\hline
\end{tabular}

$S R W=$ standardized regression weights, $V=$ variances, $R^{2}=$ squared multiple correlations.

Table 2 Summary of fit statistics for testing measurement invariance across gender $(N=613)$.

\begin{tabular}{|c|c|c|c|c|c|c|c|c|c|}
\hline Model & $\chi^{2}$ & $d f$ & RMSEA $(90 \%$ CI) & GFI & CFI & $\Delta \chi^{2}$ & $\Delta d f$ & $p$ & $\triangle C F I$ \\
\hline \multicolumn{10}{|c|}{ 1st measurement } \\
\hline \multicolumn{10}{|l|}{ Gender } \\
\hline Boys & 110.258 & 51 & $0.060(0.045-0.076)$ & 0.949 & 0.963 & & & & \\
\hline Girls & 137.477 & 51 & $0.076(0.061-0.092)$ & 0.924 & 0.891 & & & & \\
\hline $1 \mathrm{st}$ & 247.742 & 102 & $0.048(0.041-0.056)$ & 0.937 & 0.939 & & & & \\
\hline 2nd & 264.545 & 111 & $0.048(0.040-0.055)$ & 0.933 & 0.936 & 16.803 & 9 & 0.052 & 0.003 \\
\hline $3 r d$ & 281.553 & 114 & $0.049(0.042-0.056)$ & 0.929 & 0.930 & 17.008 & 3 & 0.001 & 0.006 \\
\hline 4th & 281.807 & 117 & $0.048(0.041-0.055)$ & 0.929 & 0.931 & 0.255 & 3 & 0.968 & -0.001 \\
\hline 5 th & 330.056 & 129 & $0.051(0.044-0.057)$ & 0.914 & 0.916 & 48.249 & 12 & 0.000 & 0.015 \\
\hline \multicolumn{10}{|c|}{ 2nd measurement } \\
\hline \multicolumn{10}{|l|}{ Gender } \\
\hline Boys & 159.978 & 51 & $0.082(0.067-0.096)$ & 0.924 & 0.906 & & & & \\
\hline Girls & 136.505 & 51 & $0.076(0.061-0.092)$ & 0.926 & 0.861 & & & & \\
\hline $1 \mathrm{st}$ & 296.482 & 102 & $0.056(0.049-0.063)$ & 0.925 & 0.891 & & & & \\
\hline 2nd & 305.044 & 111 & $0.053(0.046-0.061)$ & 0.923 & 0.900 & 8.561 & 9 & 0.479 & 0.000 \\
\hline $3 \mathrm{rd}$ & 319.267 & 114 & $0.054(0.047-0.061)$ & 0.920 & 0.897 & 14.224 & 3 & 0.003 & 0.005 \\
\hline 4th & 322.173 & 117 & $0.054(0.047-0.061)$ & 0.918 & 0.900 & 2.905 & 3 & 0.406 & 0.000 \\
\hline 5 th & 378.162 & 129 & $0.056(0.050-0.063)$ & 0.906 & 0.889 & 55.989 & 12 & 0.000 & 0.019 \\
\hline \multicolumn{10}{|c|}{ 3rd measurement } \\
\hline \multicolumn{10}{|l|}{ Gender } \\
\hline Boys & 126.721 & 51 & $0.068(0.053-0.083)$ & 0.940 & 0.929 & & & & \\
\hline Girls & 159.244 & 51 & $0.086(0.071-0.101)$ & 0.915 & 0.822 & & & & \\
\hline $1 \mathrm{st}$ & 285.973 & 102 & $0.054(0.047-0.062)$ & 0.928 & 0.890 & & & & \\
\hline 2 nd & 295.138 & 111 & $0.052(0.047-0.059)$ & 0.927 & 0.899 & 9.165 & 9 & 0.422 & 0.000 \\
\hline $3 \mathrm{rd}$ & 310.481 & 114 & $0.053(0.046-0.060)$ & 0.924 & 0.895 & 15.343 & 3 & 0.002 & 0.006 \\
\hline 4th & 312.802 & 117 & $0.052(0.045-0.059)$ & 0.923 & 0.898 & 2.321 & 3 & 0.508 & 0.000 \\
\hline 5 th & 347.596 & 129 & $0.053(0.046-0.059)$ & 0.911 & 0.897 & 34.794 & 12 & 0.001 & 0.010 \\
\hline
\end{tabular}

RMSEA = root mean square error of approximation; $G F I=$ goodness of fit index; $C F I=$ comparative fit index. 
the invariance analysis of the proposed model across the three measurement occasions. In model comparisons, we mainly judged model improvement on the CFI change since it is independent of both model complexity and sample size. Five comparisons in goodness-of-fit for " 1 st Model " through " 5 th Model" were performed. The first hypothesis tested was that the three-factor structure was invariant among boys and girls ("1st Model"). This model is defined to be the minimal criterion for testing factor invariance. Results of the analysis showed that the model with no constraints ("1st Model") represents a reasonable fit to the data, in all three measurements. The second hypothesis tested was a more restrictive model ("2nd Model"), specifying equal first-order factor loading among boys and girls. The specific model fitted the data well since there was no substantial difference in CFI in all three measurements $(\triangle C F I=0.003, \Delta C F I=0.000$, and $\triangle C F I=0.000)$. Similarly, results of the third hypothesis ("3rd Model") indicated that the second-order factor loadings were invariant across gender $(\triangle C F I=0.006, \triangle C F I=0.005$, and $\triangle C F I=0.006)$. Subsequently, there was no appreciable difference in the structural residuals (" 4 th
Model") between boys and girls in three measurements $(\triangle C F I=-0.001, \Delta C F I=0.000$, and $\triangle C F I=0.000)$. However, results of the fifth hypothesis of invariance of residual variance of observed variables ("5th Model"), revealed that there was a significant change in fit in all three assessment times $(\triangle C F I=0.015, \Delta C F I=0.019$, and $\triangle C F I=$ $0.010)$ across gender.

Reliability analyses indicated that the three factors of PAPBS were internally consistent. Specifically, the inter-item correlations as well as the item-total correlations were internally consistent (see Table 3). Furthermore, the Cronbach's alpha coefficients for all subscales were acceptable (see Table 3).

Finally, Pearson product moment correlations coefficients among the PAPBS subscale values and the total METs, weighted METs, and time of PA were significant moderate to high ( $>0.40$ ), ranging from -0.42 to -0.71 , in the three measurements. The higher correlations were found between mean scores of subscale "personal issues" and PA (ranged from - 0.55 to -0.62), whereas the lower ones were found between "time constraints" and PA (ranged from -0.46 to $-0.53)$. Therefore, the above results support the construct

Table 3 Internal consistency indices (mean, minimum value, maximum value) of the Physical Activity Perceived Barriers Scale $(N=613)$.

\begin{tabular}{|c|c|c|c|c|}
\hline Variables & $\begin{array}{l}\text { Item means } \\
\left(\text { Min*-Max*) }^{*}\right.\end{array}$ & $\begin{array}{l}\text { Inter-item correlations } \\
\left(\mathrm{Min}^{*}-\mathrm{Max}^{*}\right)\end{array}$ & $\begin{array}{l}\text { Item-total correlations } \\
\left(\mathrm{Min}^{*}-\mathrm{Max}^{*}\right)\end{array}$ & alpha Cronbach \\
\hline \multicolumn{5}{|l|}{ 1st measurement } \\
\hline Personal issues & $1.97(1.56-2.30)$ & $0.33(0.20-0.45)$ & $0.47(0.36-0.55)$ & 0.71 \\
\hline Environmental surroundings & $1.91(1.70-2.07)$ & $0.43(0.40-0.48)$ & $0.55(0.51-0.57)$ & 0.75 \\
\hline Time constraints & $2.80(2.62-3.04)$ & $0.63(0.56-0.67)$ & $0.70(0.66-0.74)$ & 0.83 \\
\hline Total scale & $2.16(1.56-3.04)$ & $0.33(0.19-0.67)$ & $0.53(0.30-0.57)$ & 0.86 \\
\hline \multicolumn{5}{|l|}{ 2nd measurement } \\
\hline Personal issues & $1.94(1.54-2.29)$ & $0.34(0.20-0.48)$ & $0.48(0.39-0.55)$ & 0.72 \\
\hline Environmental surroundings & $1.88(1.67-2.03)$ & $0.41(0.35-0.46)$ & $0.53(0.49-0.56)$ & 0.74 \\
\hline Time constraints & $2.77(2.56-3.02)$ & $0.59(0.51-0.64)$ & $0.66(0.62-0.72)$ & 0.81 \\
\hline Total scale & $2.13(1.54-3.02)$ & $0.33(0.20-0.64)$ & $0.53(0.46-0.59)$ & 0.86 \\
\hline \multicolumn{5}{|l|}{ 3rd measurement } \\
\hline Personal issues & $1.89(1.49-2.25)$ & $0.34(0.20-0.49)$ & $0.48(0.39-0.56)$ & 0.72 \\
\hline Environmental surroundings & $1.80(.58-1.94)$ & $0.39(0.34-0.46)$ & $0.51(0.48-0.52)$ & 0.72 \\
\hline Time constraints & $2.69(2.46-2.94)$ & $0.56(0.52-0.59)$ & $0.64(0.62-0.67)$ & 0.79 \\
\hline Total scale & $2.06(1.49-2.94)$ & $0.33(0.20-0.59)$ & $0.52(0.48-0.56)$ & 0.85 \\
\hline
\end{tabular}

$*$ Min $=$ minimum $;$ Max $=$ maximum. 
validity of the examined scale.

\section{Discussion}

Previous research suggests that perceived barriers are an important variable for predicting PA levels in children and adults. However, measurement properties of an instrument to assess the perceived barriers for PA construct have not been adequately established. In addition, each one of the dimensions that comprise this construct has not been fully identified. Therefore, the main purpose of the present work was to examine (1) factorial validity and factorial invariance across gender; (2) reliability and (3) construct validity of the PAPBS for children in the Greek-speaking population during a school year.

Regarding the analysis of the results obtained, we demonstrated that the hypothesized second-order factor model of perceived barriers for PA produced an acceptable fit for the Greek sample. More specifically, consistent with prior literature [16], we concluded that the hierarchical model in which the three factors are loading on the second-order factor fitted well the data in all three assessment times. Furthermore, the fit of the hypothesized model was at least as good, if not superior, to the results obtained with the original version of this construct. According to the results, the factor "personal issues" obtained the highest value, whereas the factor "time constraints" obtained the lowest value in all three measurements. These results are not in accordance with those obtained in similar studies $[9,16]$. Possible explanations could be related to the differences in participants' age, social differences, and not understanding correctly all the scale's items.

The present results provided support of the invariance of the first- and second-order factor loadings and invariance structural residuals, but weak support of the invariance of the residual variance of observed variables of the PAPBS among boys and girls. It is known that particular interest in second-order model is the test of invariance of structural residuals because it ensures that the unique variance of each first-order factor that is not shared by the common second order factor is the same. However, this level of invariance is more advanced and restrictive and it is usually difficult to achieve [30].

With regard to the reliability of the scale, examination of the Cronbach's alpha coefficient showed that scores on the PAPBS subscales were acceptable (> 0.70). In addition, the homogeneity of the PAPBS was confirmed by the inter-item correlation coefficients and the corrected inter-total correlations of the items in all three assessments, which are within the range recommended by many researchers [29].

Finally, the results of this study support the construct validity of the translated version of the PAPBS. The hypothesis that the perceived barriers for PA scales would be negatively related to reported PA scores (total METs, weighted METs, time of PA) was fully confirmed by the data. All correlations were above the proposed value of 0.40 [31]. As it was expected, children who reported more perceived barriers to PA participated less in moderate-to-vigorous PA. Overall, the present study confirmed the negative correlations found in previous studies [5, 11, 12], demonstrating that the scores of the PAPBS are valid.

The validity and reliability data of this study indicate that the perceived barriers to PA scale is a promising instrument that should be further investigated. However, there are several important limitations that may restrict the broader application of this study. Firstly, the study sample was selected from only one Greek city. Consequently, caution must be used when generalizing these findings to children from other Greek cities. Secondly, replication of this investigation with different populations, such as adolescents, overweight/obese or populations from other countries could strengthen conclusions regarding the validity and reliability of the examined scale. Finally, examination of the factorial invariance 
between other groups, such as children and adolescents, overweight/obese children and normal-weight children, active children and inactive children or children from high socioeconomic status and children from low socioeconomic status could support the generalisability and construct validity of the proposed scale. Despite these limitations, the examination of the psychometrics properties of PAPBS in the three measurements support the validity and reliability of the examined scale.

\section{Conclusion}

In short, the results of the present study provide support for the validity and factorial invariance across boys and girls, as well as internal consistency of PAPBS in Greek children. The scale is considered as a useful tool for research examining social-cognitive models related to PA and implementing intervention programs to increase PA levels in the Greek young population.

\section{Acknowledgments}

This project has been co-financed by the European Union (European Social Fund-ESF) and Greek national funds through the Operational Program "Education and Lifelong Learning" of the NSRF (National Strategic Reference Framework)-Research Funding Program: Heracleitus II. Investing in knowledge society through the European Social Fund.

\section{References}

[1] Janssen, I., and LeBlanc, A. 2010. "Systematic Review of the Health Benefits of Physical Activity and Fitness in School-Aged Children and Youth." International Journal of Behavioral Nutrition and Physical Activity 7: 40.

[2] Basterfield, L., Adamson, A., Maute, U., and Reilly, J. 2008. "Objectively-Measured Physical Activity of Children in the Gateshead Millennium Study." Proceedings of the Nutrition Society 1: 67.

[3] Kahn, J. A., Huang, B., Gillman, M. W., Field, A. E., Austin, S. B., Colditz, G. A., and Frazier, A. L. 2008. "Patterns and Determinants of Physical Activity in U.S. Adolescents." Journal of Adolescent Health 42 (4): 369-77.
[4] Lubans, D. R., Foster, C., and Biddle, S. J. H. 2008. "A Review of Mediators of Behavior in Interventions to Promote Physical Activity among Children and Adolescents." Preventive Medicine 47 (5): 463-70.

[5] Patnode, C. D., Lytle, L., Erickson, D. J., Sirard, J. R., Barr-Anderson, D., and Story, M. 2010. "The Relative Influence of Demographic, Individual, Social, and Environmental Factors on Physical Activity among Boys and Girls." International Journal of Behavioral Nutrition and Physical Activity 7: 79.

[6] Sallis, J., Prochaska, J., and Taylor, W. 2000. “A Review of Correlates of Physical Activity of Children and Adolescents." Medicine Science in Sport and Exercise 32 (5): 963-75.

[7] Janz, N., and Becker, M. 1984. "The Health Belief Model: A Decade Later." Health Education Quarterly 11 (1): $1-47$.

[8] Stretcher, V. S., and Rosenstock, I. M. 1997. "The Health Belief Model." In Health Behaviours and Health Education Theory, Research and Practice, edited by Glanz, K., Lewis, F. M, and Rimer, B. K. San Francisco: Jossey-Bass, 41-59.

[9] Allison, K. R., Dwyer, J. M., and Makin, S. 1999. "Perceived Barriers to Physical Activity among High School Students." Preventive Medicine 28 (6): 608-15.

[10] Hammerschmidt, P., Tackett, W., Golzynski, M., and Golzynski, D. 2010. "Barriers to and Facilitators of Healthful Eating and Physical Activity in Low-income Schools." Journal of Nutrition Education and Behavior 43 (1): 63-8.

[11] Limstrand, T. 2008. "Environmental Characteristics Relevant to Young People's Use of Sports Facilities: A Review." Scandinavian Journal of Medicine \& Science in Sports 18 (3): 275-87.

[12] Lubans, D. R., Sylva, K., and Morgan, P. J. 2007. "Factors Associated with Physical Activity in a Sample of British Secondary School Students." Australian Journal of Educational \& Developmental Psychology 7: 22-30.

[13] Brown, H., Hume, C., and ChinAPaw, M. 2009. "Validity and Reliability of Instruments to Assess Potential Mediators of Children's Physical Activity: A Systematic Review." Journal of Science and Medicine in Sport 12 (5): 539-48.

[14] Dishman, R. K., Hales, D. P., Sallis, J. F., Saunders, R., Dunn, A. L., Bedimo-Rung, A. L., and Ring, K. B. 2010. "Validity of Social-cognitive Measures for Physical Activity in Middle-school Girls." Journal of Pediatric Psychology 35 (1): 72-88.

[15] Motl, R. W., Dishman, R. K., Ward, D. S., Saunders, R. P., Dowda, M., Felton, G., and Pate, R. R.. 2005. "Perceived Physical Environment and Physical Activity 
across One Year among Adolescent Girls: Self-efficacy as a Possible Mediator." Journal of Adolescent Health 37 (5): 403-8.

[16] Wu, T-Y., Ronis, D. L., Pender, N., and Jwo, J-L. 2002. "Development of Questionnaire to Measure Physical Activity Cognitions among Taiwanese Adolescents." Preventive Medicine 35 (1): 54-64.

[17] Sallis, J. F., Strikmiller, P. K., Harsha, D. W., Feldman, H. A., Ehlinger, S., Stone, E. J., Williston, J., and Woods, S. 1996. "Validation of Interviewer- and Self-administered Physical Activity Checklists for Fifth Grade Students." Medicine \& Science in Sports \& Exercise 28 (7): 840-51.

[18] Gioxari, A., Kavouras, S. A., Tambalis, K. D., Maraki, M., Kollia, M., and Sidossis, L. S. 2013. "Reliability and Criterion Validity of the Self-administered Physical Activity Checklist in Greek Children.” European Journal of Sport Science 13 (1): 105-11.

[19] Arbuckle, J. L. 2009. Amos18 Users Guide. Chicago, IL: Amos Development Corporation.

[20] Byrne, B. M. 2001. Structural Equation Modeling with AMOS, Basic Concepts, Applications, and Programming. USA: Lawrence Erlbaum Associates, Inc.

[21] Hu, L., and Bentler, P. M. 1999. "Cut of Criteria for Fit Indexes in Covariance Structure Analysis: Conventional Criteria Versus New Alternatives." Structural Equation Modeling 6 (1): 1-55.

[22] Steiger, J. H. 1990. "Structural Model Evaluation and Modification: An Interval Estimation Approach." Multivariate Behavioral Research 25 (2): 173-80.

[23] Browne, M. W., and Cudeck, R. 1993. "Alternative Ways of Assessing Model Fit.” In Testing Structural Equation
Models, edited by Bollen, K. A., and Long, J. S. Newbury Park, CA: Sage, 136-62.

[24] Bentler, P. M., and Bonnet, D. G. 1980. "Significance Tests and Goodness of Fit in the Analysis of Covariance Structures." Psychological Bulletin 88 (3): 588-606.

[25] Marsh, H. W. 1994. "Confirmatory Factor Analysis Models of Factorial Invariance: A Multifaceted Approach." Structural Equation Modeling 1 (1): 5-34.

[26] Cheung, G. W., and Rensvold, R. B. 2002. "Evaluating Goodness-of-fit Indexes for Testing Measurement Invariance." Structural Equation Modeling 9 (2): 233-55.

[27] Asci, F. H., Eklund, R. C., Whitehead, J. R., Kirazci, S., and Koca, C. 2005. "Use of the CY-PSPP in Other Cultures: A Preliminary Investigation of its Factorial Validity for Turkish Children and Youth." Psychology of Sport and Exercise 6 (1): 33-50.

[28] Motl, R. W., Dishman, R. K., Dowda, M., and Pate, R. R. 2004. "Factorial Validity and Invariance of a Self-report Measure of Physical Activity among Adolescent Girls." Research Quarterly for Exercise and Sport 75 (3): 259-71.

[29] Tabachnick, B. G., and Fidell, I. S. 1996. Using Multivariate Statistics. New York: Harper Collins Publishers.

[30] Chen, F. F., Sousa, K. H., and West, S. G. 2005. "Testing Measurement Invariance of Second-order Factor Models.” Structural Equation Modeling 12 (3): 471-92.

[31] Reis, J. P., Dubose, K. D., Ainsworth, B. E., Macera, C. A., and Yore, M. M. 2005. "Reliability and Validity of the Occupational Physical Activity Questionnaire." Medicine \& Sciences in Sports \& Exercise 37 (12): 2075-83.

\section{Appendix A}

Table A1 Items of the Physical Activity Perceived Barriers Scale.

\begin{tabular}{ll}
\hline 1 & I don't have time. \\
2 & I have too many chores to do. \\
3 & I don't have a good place to exercise. \\
4 & I don't have right/clothes to exercise. \\
5 & I don't know how to do a certain type of exercise. \\
6 & I don't have right equipment to exercise. \\
7 & I have too much homework to do. \\
8 & I don't have anyone to exercise with. \\
9 & I don't like to exercise. \\
10 & I had PE class earlier today. \\
11 & I am too tired. \\
12 & There are other interesting things to do. \\
\hline
\end{tabular}


Table A2 Self-Administered Physical Activity Checklist (SAPAC).

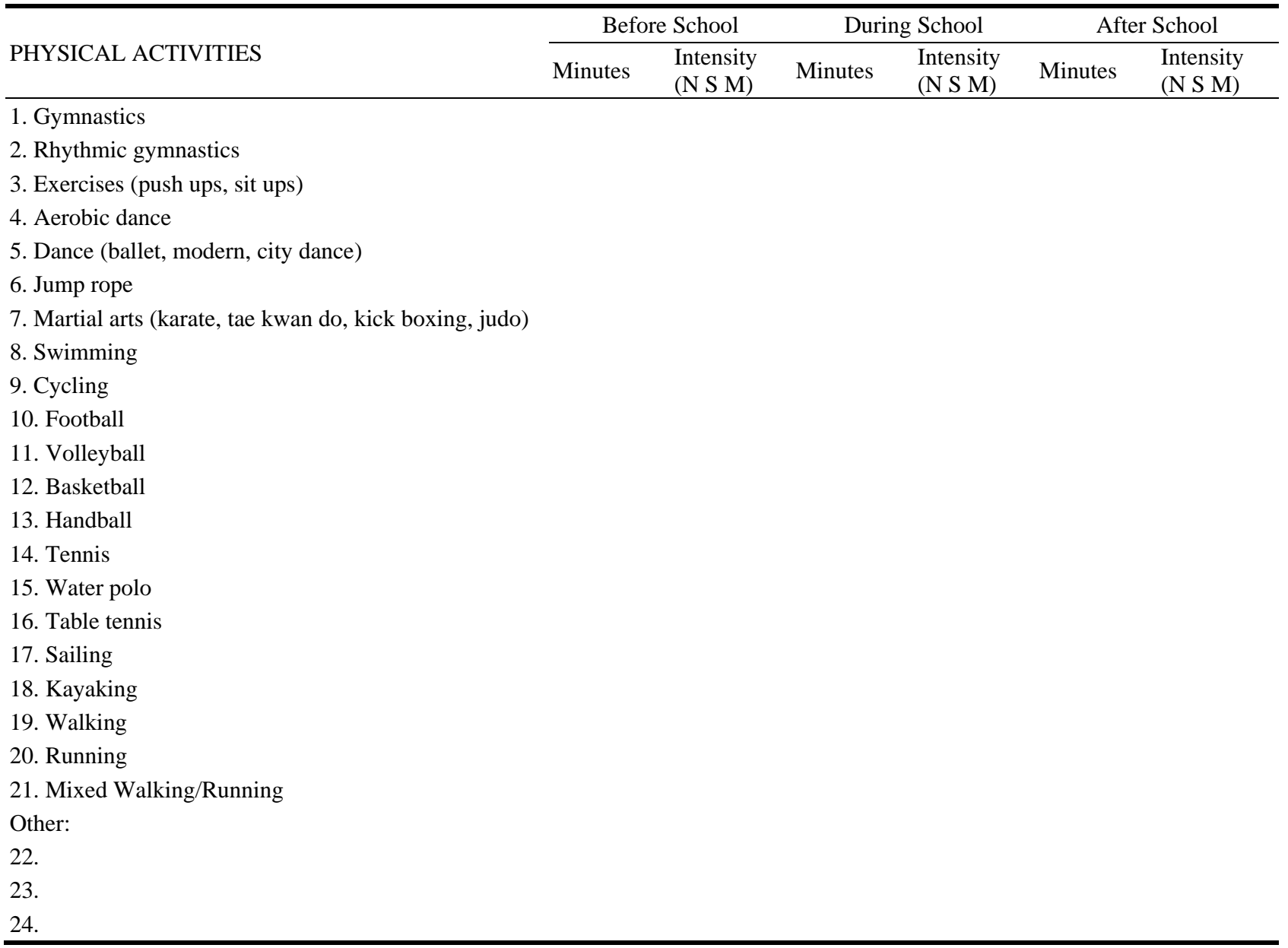

Questionnaire number.......

Date.

Remember all the physical activities that you participated in the previous day. Write the number of minutes you were doing for each of the activities you did for more than $5 \mathrm{~min}$. Did it make you breathe hard or feel tired? If you did not feel tired or breathe hard during the participation in physical activity, write the letter $\mathbf{N}$ (none). If you felt tired or breathed hard some of the time, write $\mathbf{S}$ (some). Finally, if you felt tired and breathed hard most of the time, write M (most of the time). 